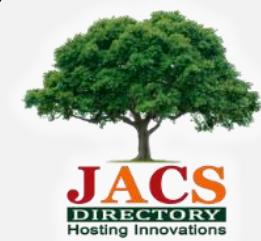

Journal of Nanoscience and Technology

\title{
Bio-Synthesis and Characterization of Copper Molybdate Nanoparticles
}

\author{
P. Santhiyadevi, K. Buvaneswari* \\ PG Department of Chemistry, Sri S.Ramasamy Naidu Memorial College (Autonomous), Sattur - 626 203, Tamil Nadu, India.
}

\section{ART IC LE DET A ILS}

\section{Article history:}

Received 09 May 2018

Accepted 17 May 2018

Available online 20 June 2018

\section{Keywords:}

$\mathrm{CuMoO}_{4}$

Phyllanthus amarus

Antimicrobial Activity

\begin{abstract}
A B S T R A C T
In the present work $\mathrm{CuMoO}_{4}$ and $\mathrm{P} / \mathrm{CuMoO}_{4}$ nanoparticles were synthesized by simple precipitation method. The synthesized molybdate nanoparticles were characterized by Fourier transform infrared spectroscopy (FT-IR), X-ray diffraction (XRD), scanning electron microscopy (SEM) and UV-visible diffuse reflectance spectroscopy (UV-vis DRS). XRD results show that the average crystalline size of $\mathrm{CuMoO}_{4}$ and $\mathrm{P} / \mathrm{CuMoO}_{4}$ nanoparticles were found to be $62.9 \mathrm{~nm}$ and $59.7 \mathrm{~nm}$ respectively. SEM results showed that $\mathrm{CuMoO}_{4}$ nanoparticles composed of sphere like structure and $\mathrm{P} / \mathrm{CuMoO}_{4}$ with agglomeration. Four absorption bands at 721, 828, 898 and $967 \mathrm{~cm}^{-1}$ were observed in FT-IR spectrum. The sharp adsorption peak at 270-350 nm was observed in UV-vis DRS technique. The antimicrobial activities of synthesized nanoparticles were observed against various pathogens.
\end{abstract}

\section{Introduction}

Metal molybdate with formula $\mathrm{MMoO}_{4}$ have attracted much attention due to their interesting size and shape dependent optical, magnetic and electronic properties [1-6]. Transition metal molybdate have many applications, such as in gas sensors, optical fibers, humidity sensors, pigments, catalytic and biological activity. Copper molybdate $\left(\mathrm{CuMoO}_{4}\right)$ is one of the important inorganic materials that have high potential application in various fields such as catalysts, humidity sensor, photo anodes, laser hosts, microwave application and optical fibers. Also it is considered to be a potential candidate as a visible light photocatalyst for organic contaminants decomposition. Recently, many studies have been reported on the preparation and characterization of copper molybdate such as precipitation [7], hydrothermal [8], flame spray method [9]. However, these methods usually require special equipment, high temperature, templates or substrate and usually result in impurities. The toxic chemicals, non-polar solvent and synthetic additives or capping agent immersing from the chemical reaction are often potentially dangerous to the environment.

The plant with the antioxidant or reducing properties is usually responsible for the reduction of metal compounds into their respective nanoparticles. According to the researchers, the poly phenol components present in the plant extract are responsible for the reduction of metal ions, whereas water soluble heterocyclic components stabilize the formed nanoparticles. The synthesized nanoparticles have shown considerable stability and it was found to have potential for bio-application.

Researchers studied photocatalytic degradation of 4-chloro phenol by copper molybdate doped titanium oxide and the structural and optical properties of molybdate were also reported in various work [10-14]. The synthesis of nano-size $\mathrm{CuMoO}_{4}$ crystals includes co-precipitation, polymeric precursor method, modified citrate complex technique, hydrothermal method, molten salt method and spray pyrolysis [15-20]. Hence developing of reliable biosynthetic, an environment friendly approach have been added much importance because of its eco-friendly products, biocompatibility and economic viability in the long run and also to avoid adverse effects during their environmental application. In this work, we adopted a precipitation route for the synthesis of $\mathrm{CuMoO}_{4}$ pure phase with uniform particle size distribution and plant extract as capping agent. $\mathrm{CuMoO}_{4}$ nanoparticles were explored with respect to their prospective anti-malarial application.

\section{Experimental Methods}

\subsection{Materials}

AR grade of sodium molybdate, copper acetate and urea were used as received from Merck. FT-IR spectra of the sample were measured in the $\mathrm{KBr}$ pellet in the range of $400 \mathrm{~cm}^{-1}$ to $4000 \mathrm{~cm}^{-1}$ using Shimadzu spectrometer. UV-visible spectra of the sample were measured in UV-2400 PC SERIES having range $200-900 \mathrm{~cm}^{-1}$. XRD analysis was carried on atomic X-ray diffraction $\left((1.54 \AA)\right.$ with a scanning speed of $10^{\circ} / \mathrm{min}$. SEM images were taken with a HITACHI Model S-3000H instrument.

\subsection{Preparation of Plant Extract}

The collected Phyllanthus amarus leaves were washed thrice with tap water and twice with distilled water to remove the adhering salts and other associated contaminants. $10 \mathrm{~g}$ of leaf was taken and boiled with 100 $\mathrm{mL}$ of sterile distilled water at $100{ }^{\circ} \mathrm{C}$ for half an hour. The boiled extract was filtered through Whatman No.1 and was stored in refrigerator at $4{ }^{\circ} \mathrm{C}$ for further studies [21].

\subsection{Preparation of $\mathrm{CuMoO}_{4}$ Nanoparticles}

Copper molybdate nano particle were prepared by simple precipitation method. 1:0.5 molar ratio of copper acetate and sodium molybdate were dissolved in $40 \mathrm{~mL}$ distilled water in two glass beaker and $0.5 \mathrm{~g}$ of urea were dissolved in $10 \mathrm{~mL}$ of distilled water. The above solution was mixed well and stirring for 30 minutes. Again the same procedure was repeated and then $5 \mathrm{~mL}$ of plant extract was added and it was stirred for 2 hours to form a homogeneous precipitate. After filtering the precipitate washed with distilled water and dried at $80{ }^{\circ} \mathrm{C}$ for 5 hours. The obtained nanoparticle was calcinated at $550^{\circ} \mathrm{C}$ for 4 hours to get final product [22].

\section{Results and Discussion}

\subsection{UV-Visible Diffuse Reflectance Spectra Analysis}

The optical absorption properties of $\mathrm{CuMoO}_{4}$ were characterized by UV-vis absorption spectroscopy (DRS-mode). The UV-visible DRS absorption spectrum of synthesized $\mathrm{CuMoO}_{4}$ nanopartices is shown in Fig. 1. The sharp adsorption steep in the region of $270-350 \mathrm{~nm}$ which is the characteristic peak of $\mathrm{CuMoO}_{4}$ nanoparticles. This result strongly confirms the small crystal size of the product particles, which could be ascribed to the strong quantum confinement of the excitonic transition of the nanostructures. 


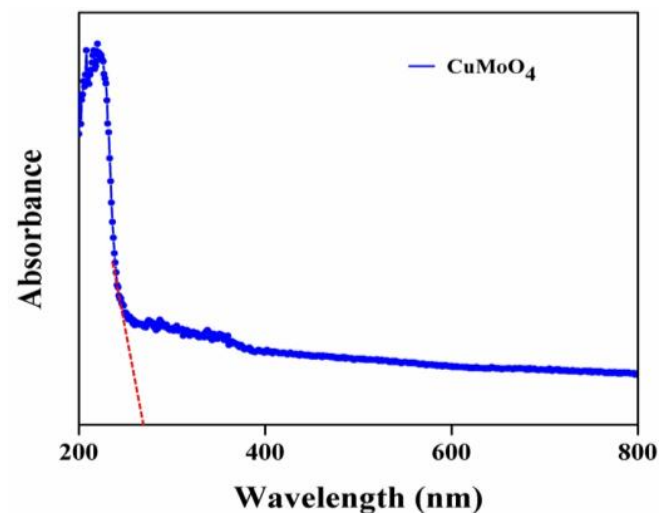

Fig. 1 UV-visible DRS spectra of $\mathrm{CuMoO}_{4}$

\subsection{X-Ray Diffraction (XRD) Analysis}

The crystalline phase and the crystalline nature of the synthesized $\mathrm{CuMoO}_{4}$ were analyzed using XRD which is shown in Fig. 2. The diffraction peaks of $\mathrm{CuMoO}_{4}$ match well with the standard card of $\mathrm{CuMoO}_{4}$ (JCPDS card No. 36-0405). The characteristic $2 \theta$ regions of $15.85,19.50,24.91$, $26.78,29.89,32.87,33.34,34.53,35.69,41.19,44.53,47.15$ and $52.56^{\circ}$ were corresponds to the reflections of planes of $\mathrm{CuMoO}_{4}(020),(110)$, (031), (111), (121), (200), (002), (221), (122) (151), (202), (241) and (212) respectively. The XRD pattern of the $\mathrm{P} / \mathrm{CuMoO}_{4}$ has shown the high intense diffraction peak consists of characteristic peak of both $\mathrm{CuMoO}_{4}$ as well as the diffraction peak of plant which clearly suggests that formation of $\mathrm{P} / \mathrm{CuMoO}_{4}$. The strong and sharp diffraction peaks of $\mathrm{P} / \mathrm{CuMoO}_{4}$ indicated the good crystallinity of the nanoparticles. The average crystallite size of the $\mathrm{CuMoO}_{4}$ and $\mathrm{P} / \mathrm{CuMoO}_{4}$ nanoparticles were determined by the full width at half maximum (FWHM) of the X-ray diffraction peak using Debye Scherer's equation [23], $D=\mathrm{K} \lambda / \beta \cos \theta$, where $D$ is the crystallite, $\lambda$ is the $\mathrm{X}$-ray wavelength, $\beta$ is the Full Width at Half Maximum (FWHM) of the diffraction peak, $\theta$ is the diffraction angle and $\mathrm{k}$ is the Scherer's constant of the order unity. The crystallite sizes were calculated for the reflection of the plane $\mathrm{CuMoO}_{4}$ and $\mathrm{P} / \mathrm{CuMoO}_{4}$ nanoparticles was $62.9 \mathrm{~nm}$ and $59.7 \mathrm{~nm}$ respectively.

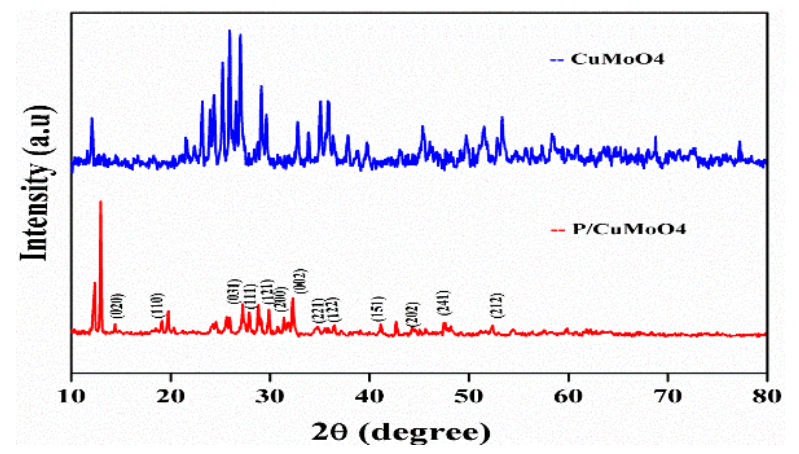

Fig. 2 XRD pattern of $\mathrm{CuMoO}_{4}$ and $\mathrm{PCuMoO}_{4}$

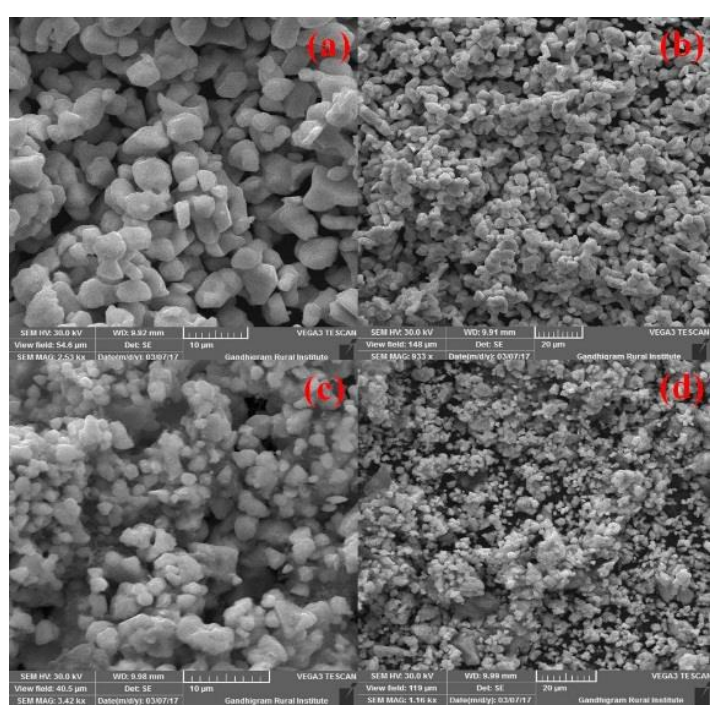

Fig. 3 SEM image of (a, b) $\mathrm{CuMoO}_{4}$ and (c, d) $\mathrm{PCuMoO}_{4}$ https://doi.org/10.30799/jnst.120.18040403

\subsection{SEM Analysis}

The morphology of synthesized $\mathrm{CuMoO}_{4}$ and $\mathrm{P} / \mathrm{CuMoO}_{4}$ was studied by scanning electron microscopy. The SEM micrographs of the pristine $\mathrm{CuMoO}_{4}$ given in Fig. 3(a) indicated that the sphere like particles and Fig. 3(b) which closely attached to each other particles the $\mathrm{CuMoO}_{4}$ surface was very smooth and shining. The $\mathrm{SEM}$ micrographs of $\mathrm{P} / \mathrm{CuMoO}_{4}$ showed that there is no agglomeration of $\mathrm{CuMoO}_{4}$ nanoparticle in the plant matrix and it was uniformly distributed throughout the plant matrix which is shown in Figs. 3c and d.

\subsection{FT-IR Spectroscopy}

To confirm the structural information of $\mathrm{CuMoO}_{4}$ and $\mathrm{P} / \mathrm{CuMoO}_{4} \mathrm{Nps}$ was further evidenced by FT-IR analysis which is shown in Fig. 4. FT-IR spectra of $\mathrm{P} / \mathrm{CuMoO}_{4}$ showed absorption peaks at $500-650 \mathrm{~cm}^{-1}$ which is the characteristic peak of $\mathrm{Cu}-\mathrm{O}$ bond. However, in the FT-IR spectrum of the synthesized $\mathrm{CuMoO}_{4} \mathrm{Nps}$ four absorption bands (at 721, 828, 898, 967 $\mathrm{cm}^{-1}$ ) are observed. The band at $1634 \mathrm{~cm}^{-1}$ was attributed to the metal bonded stretching vibration of $\mathrm{C}-\mathrm{O}$ groups. The absorption band around $3430 \mathrm{~cm}^{-1}$ which corresponds to the $\mathrm{O}-\mathrm{H}$ stretching vibration indicating the presence of hydroxyl groups [24, 25]. No other absorption band except the above mentioned was detected in the observed FT-IR spectrum.

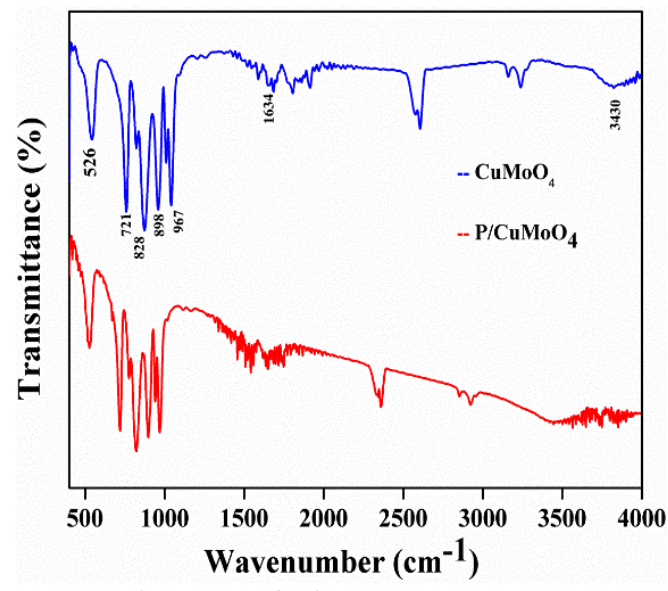

Fig. 4 FT-IR spectra of $\mathrm{CuMoO}_{4}$ and $\mathrm{P} / \mathrm{CuMoO}_{4}$

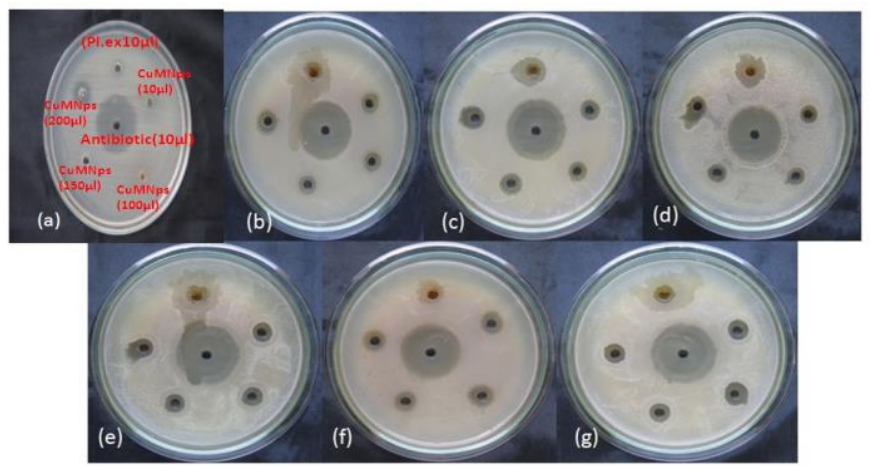

Fig. 5 Zone inhibition of different pathogens a) Bacillus subtillis, b) Staphylococcus aureus, c) Streptococcus faecalis, d) Candida albicans, e) Klebsiella pneumoniae, f) Pseudomonas aeruginosa and g) E. coli by $\mathrm{CuMoO}_{4}$ NPs synthesized at $1 \mathrm{mM}$ concentration

\subsection{Antimicrobial Activity of Green Synthesized Copper Molybdate Nanoparticles}

Due to higher simplicity and eco friendliness, the plant mediated synthesis of nanoparticles gains much importance in this modern era. The presence of phytochemicals in the plants have tendency to reduce the heavy metals from their higher oxidation state to zero oxidation state. For the production of nanoparticles, the electron rich phytochemicals in plants acts as the building block for conversion of metallic precursor, there by replacing the toxic reducing agents $[26,27]$ to design engineered nanomaterials in medicine, energy, electronics, etc., the green eco-friendly technique is used. The mechanism between the nanoparticles and the microorganism takes place by the electrostatic interaction of positively charged nanoparticles with that of the negatively charged microorganisms. As copper molybdate nanoparticles are having greater surface area and exclusive size, it has an easier tendency to reach the nuclear content of bacteria [28]. Agar diffusion method was adopted for 
the determination of the antimicrobial activity using different pathogens such as the gram positive (Staphylococcus aureus, Streptococcus sp and Bacillus subtilis) bacterial colonies, gram positive bacterial (E. coli, Klebsiella pneumoniae, Pseudomonas aeruginosa) colonies and fungus (Candida albicans). Nutrient broth was prepared freshly and was incubated. The culture, the plant extracts, the synthesized copper molybdate nanoparticles were loaded using a sterile rod and the plates were incubated for 1 day. After incubation period the zone of inhibition was measured and given in Fig. 5. The maximum zone of inhibition was measured for the bacterial strain the Streptococcus faecalis followed by the strain staphylococcus aureus. The synthesized molybdate nanoparticle comprises activity towards the pathogens can be used as a drug in a thriving approach.

Table 1 ZOI of pathogen by copper molybdate nanoparticle

\begin{tabular}{lll}
\hline Organisms & \multicolumn{2}{l}{ Concentration of extract and zone inhibition $(\mathrm{mm})$} \\
\cline { 2 - 3 } & $\mathrm{PCuMoO}_{4}(100 \mu \mathrm{L})$ & $\mathrm{CuMoO}_{4}(100 \mu \mathrm{L})$ \\
\hline Bacillus subtillis & 19 & 18 \\
Staphylococcus aureus & 22 & 21 \\
Streptococcus faecalis & 24 & 23 \\
Candida albicans & 18 & 25 \\
Klebsiella pneumoniae & 21 & 23 \\
Pseudomonas aeruginosa & 17 & 20 \\
E. coli & 19 & 21 \\
\hline
\end{tabular}

\section{Conclusion}

The copper molybdate nanoparticles were successfully synthesized by using Phyllanthus amarus plant which provides cost effective, easy and proficient way for synthesis of $\mathrm{CuMoO}_{4}$ nanoparticles. The functional group present in the leaf extract has been confirmed by FT-IR. The polyphenols of leaf extract were mainly responsible for the reduction of copper molybdate metal ion into nanoparticles. The synthesized copper molybdate nanoparticles were analyzed using FT-IR, UV-DRS, XRD and SEM. Copper molybdate nanoparticle were effectively utilized for the antimicrobial study. The maximum ZOI was found to be more in gram positive bacteria when compared to gram-negative bacteria. The Phyllanthus amarus plant may be effectively utilized for the production of copper molybdate nanoparticle with economically for many pharmaceutical applications.

\section{References}

[1] H. Ehrenberg, M. Wiesmann, J. Garcia-Jaca, H. Weitzel, H. Fuess, Magnetic structures of the high-pressure modifications of $\mathrm{CoMoO}_{4}$ and $\mathrm{CuMoO}_{4}$, J. Magn. Magn. Mater. 182 (1998) 152-160.

[2] F. Rodríguez, D. Hernández, J. Garcia-Jaca, H. Ehrenberg, H. Weitzel, Optical study of the piezochromic transition in $\mathrm{CuMoO}_{4}$ by pressure spectroscopy, Phys. Rev. 61 (2000) 16497-16501.

[3] M. Sadeghi, Investigation of the structural, optical and magnetic properties of $\mathrm{CuMoO}_{4}$ nanoparticles synthesized through a sonochemical method, J. Mater. Sci. Mater. Electron. 27 (2016) 5796-5801.

[4] A.W. Sleight, B.L. Chamberland, Transition metal molybdates of the type $\mathrm{AMoO}_{4}$, Inorg. Chem. 7 (1968) 1672-1675.

[5] S. Dola, T.V. Kumar, S.D. Ephraim, Synthesis and spectroscopic analysis of $\mathrm{CuMoO}_{4}-\mathrm{MoO}_{3}$ nanocomposite, Adv. Eng. Appl. 5 (2015) 1-6.

[6] M. Benchikhi, R. ElOuatib, S.G. Fritsch, L. Er-Rakho, B. Durand, Characterization and photoluminescence properties of ultrafine copper molybdate $(\alpha-$
$\mathrm{CuMoO}_{4}$ ) powders prepared via a combustion-like process, Int. J. Min Met Mater. 11 (2016) 1340-1345.

[7] M.R. Nasrabadi, S.M. Pourmortazavi, M.K. Shalamzari, Facile chemical synthesis, structure characterization of copper molybdate nanoparticles, J. Mol. Struct. 1083 (2015) 229-235.

[8] M. Najai, A. Abbasi, M. Masteri-Farahani, Preparation of $\mathrm{MoO}_{3} / \mathrm{CuMoO}_{4}$ nanoparticles as selective catalyst for olefin epoxidation, Scentia Iranica 24 (2017) 1203-1208

[9] M. Høj, K. Linde, T.K. Hansen, M. Brorson, A.D. Jensen, J.D. Grunwaldt, Flame spray synthesis of $\mathrm{CoMoO}_{4} / \mathrm{Al}_{2} \mathrm{O}_{3}$ hydrotreating catalysts, Appl. Catal. A 397 (2011) 201-208.

[10] T.K. Ghorai, Photocatalytic degradation of 4-chlorophenol by $\mathrm{CuMoO}_{4}$-doped $\mathrm{TiO}_{2}$ nanoparticles synthesized by chemical route, Open. J .Phys. Chem. 1 (2011) 28-36.

[11] R. Sundaram, K.S. Nagaraja, Solid state electrical conductivity and humidity sensing studies on metalmolybdate-molybdenum trioxide composites $(\mathrm{M}=$ $\mathrm{Ni}^{2+} \mathrm{Cu}^{2+}$ and $\mathrm{Pb}^{2+}$ ), Sens. Actuat. B Chem. 101 (2004) 353-360.

[12] H. Wan, J. Jiang, X. Ji, L. Miao, L. Zhang, K. Xu, H. Chen, Y. Ruan, Rapid microwave-assisted synthesis of $\mathrm{NiMoO}_{4} \cdot \mathrm{H}_{2} \mathrm{O}$ nanoclusters for supercapacitors, Mater. Lett. 108 (2013) 164-167.

[13] D. Cai, B. Liu, D. Wang, Y. Liu, L. Wang, H. Li, Y. Wang, Facile hydrothermal synthesis of hierarchical ultrathin mesoporous $\mathrm{NiMoO}_{4}$ nanosheets for high performance super capacitors, Electrochim. Acta 115 (2014) 358-363.

[14] W.P. Doyle, G. McGuire, G.M. Clark, Preparation and properties of transition metal molybdate (VI), J. Inorg. Nucl. Chem. 28 (1966) 1185-1190.

[15] P. Schmitt, N. Brem, S. Schunk, C. Feldmann, Polyol-mediated synthesis and properties of nanoscale molybdates/tungstates: color, luminescence, catalysis, Adv. Funct. Mater. 21 (2011) 3037-3046.

[16] B. Swain, D.H. Lee, J.R. Park, C.G. Lee , K.J. Lee, D.W. Kim, K.S. Park, Synthesis of $\mathrm{Cu}_{3}\left(\mathrm{MoO}_{4}\right)_{2}(\mathrm{OH})_{2}$ nanostructures by simple aqueous precipitation: understanding the fundamental chemistry and growth mechanism, Cryst. Eng. Comm. 19 (2017) 154-165.

[17] N.V. Lebukhova, The structural catalyst $\mathrm{CuMoO}_{4} / \mathrm{TiO}_{2} / \mathrm{TiO}_{2}+\mathrm{SiO}_{2} / \mathrm{Ti}$ for diesel soot combustion, Surf. Coat. Technol. 261 (2015) 344-349.

[18] A. Sajad, S. Mohammad, S.N. Masoud, Synthesis and characterization of cerium molybdate nanostructures via a simple solvothermal method and investigation of their photocatalytic activity, J. Mater. Sci. Mater. Electron. 27 (2016) 73427352.

[19] L. Wei, L. Xuan, W. LI-li, Hydrothermal synthesis and spectral properties of $\mathrm{MMoO}_{4}: \mathrm{Eu}^{3+}(\mathrm{M}=\mathrm{Ca}, \mathrm{Sr}, \mathrm{Ba})$ red phosphors, J .Lumin. 32 (2011) 670-674.

[20] H. Lakhlifi, M. Benchikhi, R. El Ouatib, L. Er-Rakho, S. Guillemet-Fritsch, B. Durand, Synthesis and physicochemical characterization of pigments based on molybdenum ZnO-MoO Co $^{2+}$, J. Mater. Environ. Sci. 6 (2015) 3465-3469.

[21] P. Dauthal, M. Mukhopadhyay, Biofabrication, characterization, and possible bioreduction mechanism of platinum nanoparticles mediated by agroindustrial waste and their catalytic activity, Ind. Eng. Chem. Res. 52-51 (2013) 18131-18139.

[22] N.V. Suramwar, S.R. Thakare, N.T. Khaty, One pot synthesis of copper nanoparticles at room temperature and its catalytic activity, Arabian J. Chem. 9 (2016) S1807-S1812.

[23] M.S. Usman, M. E. Zowalaty, K. Shameli, N. Zainuddin, M. Salama, N.A. Ibrahim, Synthesis, characterization, and antimicrobial properties of copper nanoparticles, Int. J. Nanomed. 8 (2013) 4467-4479.

[24] J.D. Visurraga, C. Daza, C. Pozo, A. Becerra, C.V. Plessing, A. García, Study on antibacterial alginate-stabilized copper nanoparticles by FT-IR and 2D-IR correlation spectroscopy, Int .J. Nanomed. 7 (2012) 3597-3612.

[25] Z. Shahri, M.S. Niasari, N. Mir, Facile synthesis and characterization of nanostructured flower like copper molybdate by the co-precipitation method. J. Cryst. Growth 386 (2014) 80-87.

[26] N.R. Bhalodia, V.J. Shukla, Antibacterial and antifungal activities from leaf extracts of Cassia fistula L.: An ethno medicinal plant, Adv. Pharm .Technol. Res. 2 (2011) 104-109.

[27] D. Tanasic, A. Rathner, Silver, calcium, and copper molybdate compounds: Preparation, antibacterial activity and mechanisms, Colloids Surf. B Biointerf. 12 (2017) 1934-1938.

[28] Y.Y. Meng, Z.X. Xiong, Preparation of molybdates with antibacterial property, Key. Eng. Mater. 368 (2008) 1516-1518. 